BULLETIN Bulletin hispanique

HISPANIQUE Université Michel de Montaigne Bordeaux

119-1 | 2017

Autorité et pouvoir dans le théâtre du Siècle d'Or

\title{
Amarilis
}

“primicia" del imperio español y de la línea equinoccial, sirena

\section{Martina Vinatea-Recoba}

\section{CpenEdition}

Journals

Edición electrónica

URL: http://journals.openedition.org/bulletinhispanique/4942

DOI: 10.4000/bulletinhispanique.4942

ISBN: 979-10-300-0142-6

ISSN: 1775-3821

Editor

Presses universitaires de Bordeaux

Edición impresa

Fecha de publicación: 15 junio 2017

Paginación: 299-314

ISBN: 979-10-300-0141-9

ISSN: 0007-4640

Referencia electrónica

Martina Vinatea-Recoba, « Amarilis », Bulletin hispanique [En línea], 119-1 | 2017, Publicado el 15 junio 2020, consultado el 10 septiembre 2020. URL : http://journals.openedition.org/bulletinhispanique/ 4942 ; DOI : https://doi.org/10.4000/bulletinhispanique.4942 


\title{
Amarilis, "primicia" del imperio español y de la línea equinoccial, sirena ${ }^{1}$
}

\author{
Martina Vinatea-Recoba \\ Universidad del Pacifico - Perú
}

L'objectif de cet article est de mettre en évidence, en contrepoint, dans la Epistola de Amarilis a Belardo (Epître d'Amarilis à Belardo), les formules discursives qui révèlent l'ambiguïté de ce qui a été appelé «le sujet créole». L'étude montre que si, d'une part, Amarilis s'identifie à l'Empire espagnol, elle est, d'autre part, fière de son pays et de son héritage américain.

Mots-clés: Epistola de Amarilis a Belardo, Lope de Vega, sujet créole, Vice-royauté du Pérou, poésie conventuelle.

El propósito de este trabajo es mostrar en la Epistola de Amarilis a Belardo, en contrapunto, las expresiones discursivas que revelan la ambigüedad de lo que se ha llamado «el sujeto criollo». Por un lado, se evidencia la identificación de Amarilis con el Imperio espańol y, por otro, que ella se enorgullece de su tierra y del legado americano.

Palabras claves: Epistola de Amarilis a Belardo, Lope de Vega, sujeto criollo, Virreinato peruano, poesía conventual.

The purpose of this work is to demonstrate in the "Epistola de Amarilis a Belardo" (Epistle of Amarilis to Belardo), in counterpoint, the discursive expressions that reveal the ambiguity of the so called "Creole subject». On the one hand, the identification of Amarilis with the Spanish Empire is proved and, on the other hand, she prides herself of her homeland and of the American legacy.

Keywords: Amarilis Epistle to Belardo, Lope de Vega, Creole Subject, Peruvian Viceroyalty, conventual poetry.

1. Este artículo se inserta en el marco del proyecto de investigación FFI2014-52007-P, «Autoridad y poder en el teatro del Siglo de Oro. Estrategias, géneros, imágenes en la primera globalización», financiado por el Ministerio de Economía y Competitividad del gobierno de España. 
Ahora creo y con razón lo fundo, Amarilis indiana, que estoy muerto, pues que vos me escribís de otro mundo.

Lo que en duda temí, tendré por cierto, pues desde el Mar del Sur, nave de pluma en las puertas del alma toma puerto.

¡Qué clara, qué copiosa y dulce suma! Nunca la hermosa vida de su dueño voraz el tiempo consumir presuma.

Bien sé que en responder crédito empeño, vos de la línea equinoccial, sirena, me despertáis de tan profundo sueño.

Qué rica tela, qué abundante y llena de cuanto al más retórico acompańa, que bien parece que es indiana vena.

Yo no lo niego, ingenios tiene España, libros dirán lo que la Musa luce, y en propia rima, imitación extraña.

Mas los que el clima antártico produce sutiles son, notables son en todo, lisonja aquí ni emulación me induce.

Lope de Vega, Epístola séptima "Belardo a Amarilis", La Filomena y otras diversas rimas, Barcelona, Cormellas, 1621

\section{Marco histórico en el que se inserta la Epístola de Amarilis a Belardo ${ }^{2}$}

A pocos años de la conquista, entre mediados y fines del siglo XVI, en los centros administrativos virreinales de México y de Lima, principalmente, se desarrolló una importante actividad cultural ${ }^{3}$. Una década después de la creación del Virreinato del Perú, se abrieron en estas tierras centros de enseñanzas como colegios mayores y universidades. El primer libro producido en la América austral vio la luz pública en 1584, Doctrina Cristiana, texto pastoral en castellano, quechua y aymara, resultado de las sesiones del $\mathrm{III}^{\mathrm{e}}$ Concilio Limense e impreso por el turinés Antonio Ricardo.

De igual modo, a inicios del siglo XVII, Lima era una ciudad importante en tanto capital de un Virreinato cuya extensión abarcaba el territorio que en

2. Las reflexiones de este capítulo toman como base el estudio preliminar de la Epistola de Amarilis a Belardo, estudio, edición y notas de Martina Vinatea Recoba, Madrid, IberoamericanaVervuert, 2009, pp. 15-26. Todas las menciones de la Epistola del presente artículo se refieren a esta edición.

3. Según afirma Leonard, «De ser un descampado donde brutales rufianes se mataban entre sí por acaparar la parte del león de los despojos de la conquista, la "Ciudad de los Reyes" se transformó en el centro cultural más importante del sur del hemisferio. A juzgar por un pedido de libros de 1583, la región contaba con un público que demandaba lo mejor y lo más reciente que producían las prensas españolas.» Irving Leonard, Los libros del conquistador, México, Fondo de Cultura Económica, 1996, p. 182. 
la actualidad ocupan ocho países: Panamá, Ecuador, Perú, Bolivia, Paraguay, Uruguay, Argentina y Chile. En ella, vivían el virrey y el arzobispo ${ }^{4}$. Fue el emporio financiero de la América Austral. Asimismo, fue sede de la audiencia y cabecera de distrito del Tribunal de la Santa Inquisición, tuvo representación en las Cortes y fue cuna de la primera santa del Nuevo Mundo: Santa Rosa de Lima. En las artes plásticas, la influencia del arte italiano se presenta desde fines del siglo XVI con la presencia de tres pintores italianos: el hermano jesuita Bernardo Bitti, Mateo Pérez de Alessio y Angelino Medoro. Además, lienzos de importantes pintores europeos, como el flamenco Maarten o Martín de Vos, decoraron muros de iglesias y claustros. A fines del siglo XVI, se representaban obras de teatro tanto de carácter sacro como profano, en las festividades del calendario religioso -especialmente en la del Corpus Christi- y se instaló el primer corral de comedias ${ }^{6}$.

Por otro lado, se han estudiado vastamente el comercio y la circulación de obras de autores de la antigüedad y de contemporáneos que pasaron a formar parte de bibliotecas particulares como evidencia del valor asignado a la cultura en la naciente sociedad virreinal ${ }^{7}$.

Al panorama anterior, se debe agregar la actividad literaria de los autores que, entre la última década del siglo XVI y las tres primeras del XVII, desplegaron su labor literaria y conformaron la llamada Academia Antártica ${ }^{8}$. En realidad,

4. Los virreyes que gobernaron el Perú entre fines del s. XVI y principios del s. XVII fueron García Hurtado de Mendoza y Manríquez, Segundo Marqués de Cañete (1585-1596); Luis de Velasco, Marqués de Salinas (1596-1604); Gaspar de Zúńiga y Acevedo, Conde de Monterrey (1604-1606); Juan de Mendoza y Luna, Marqués de Montesclaros (1607-1615); Felipe de Borja y Aragón, Príncipe de Esquilache (1616-1621). Todos ellos gobernaron bajo los reyes de la casa real de los Austrias, Felipe II y Felipe III.

5. Los Arzobispos de Lima entre fines del s. XVI y principios del s. XVII fueron Toribio de Mogrovejo (1579-1606) y Bartolomé Lobo Guerrero (1609-1622).

6. Guillermo Lohmann, Apuntaciones sobre el arte dramático en Lima durante el Virreinato, Lima, Ed. Lumen S.A., 1941.

7. Sobre el tema, véase Guillermo Lohmann, «Libros, libreros y bibliotecas en la época virreinal», Fénix 21, 1971, pp. 17-24. Pedro Guibovich, "Libros para ser vendidos en el virreinato del Perú a fines del siglo XVI», Boletín del Instituto Riva-Agüero, 1984-1985, pp. 85114; «Las lecturas de Francisco de Isásaga», Histórica, 1986, pp. 191-212; «The Printing Press in Colonial Peru: Production, Process and Literary Categories in Lima, 1584-1699", Colonial Latin American Review, 2001, 167-188.

8. A pesar de que, en los últimos años, varios autores han retomado el tema, el trabajo más significativo respecto de la Academia Antártica sigue siendo el de Alberto Tauro, Esquividad y gloria de la Academia Antártica, Lima, Ed. Huascarán, 1948. Véase además Sonia Rose, "Hacia un estudio de las élites letradas en el Perú virreinal: el caso de la Academia Antártica», Mónica Quijada y Jesús Bustamante (eds.), Élites intelectuales y modelos colectivos, Mundo Ibérico, Madrid, Consejo Superior de Investigaciones Científicas, pp. 119.130. Adriana Valdés, «El espacio literario en la colonia», Ana Pizarro (ed.), América Latina: palabra, literatura y cultura, San Pablo, Unicamp, 1994, pp. 467-485. Rosa García Gutiérrez, «Arias Montano en el Perú: La Academia Antártica de Lima y su Discurso en loor de la poesía», Luis Gómez Canseco, Anatomía del Humanismo: Benito Arias Montano 1598-1998: Homenaje al profesor Melquiades Andrés Martín, Actas del Simposio Internacional celebrado en la Universidad de Huelva del 4 al 6 de Noviembre de 1998, 1998, pp. 319-339. Carmen Perilli de Rush, "Los enigmas de una 
esta denominación no asegura que los autores se hayan reunido formalmente en sesiones como habitualmente ocurría en este tipo de instituciones ${ }^{9}$; sin embargo, sí se puede afirmar que existió un grupo de poetas que se identificaron con los ideales y el estilo renacentistas, que «trajeron consigo una larga tradición poética entroncada en sus varias vertientes con la lírica trovadoresca, la galaicoportuguesa y la mozárabe, todas enriquecidas por la veta popular. En su modalidad lírica esta tradición se nutrió durante el siglo XVI de la poesía renacentista que renovó su contenido, métrica y estilo» ${ }^{10}$. El intento de los poetas de la Academia Antártica fue que se gestara un «proyecto de promover un humanismo intercontinental, un universalismo de nuevo signo [...] que debía reivindicar a la Colonia como locus productor de cultura capaz de desafiar los fundamentos mismos del exclusivismo europeo» ${ }^{11}$. Probablemente, por ello, se insistiera en la calificación geográfica en el título de algunas de las obras: Miscelánea antártica de Cabello de Balboa (1586); Miscelánea Austral de Ávalos y Figueroa (1602); Parnaso Antártico de Mexía de Fernangil (1608); Armas Antárticas de Miramontes y Zuázola (1615).

Los miembros de la Academia Antártica presentan la visión del llamado «sujeto colonial» colonizador definido a partir de cómo se ve y no de quién $\mathrm{es}^{12}$. Son poetas que presentan una visión europeizante que concuerda con los valores de la cultura imperial espańola: masculina, caballeresca y cristiana ${ }^{13}$. Agreguemos a esta idea la "adhesión a la norma hispánica» de la que habla Ángel Rama y según la que la «consagración cultural derivaba del uso de la lengua que distinguía a los miembros del cogollo superior. La propiedad y la lengua delimitaban la clase dirigente» ${ }^{14}$.

Para la determinación del grupo que conformó esta Academia, se cuenta con tres testimonios importantes: el Canto de Calíope (1585), de Miguel

dama y la fundación de la crítica latinoamericana: el Discurso en loor de la poesía», Etiópicas 1, 2004-2005, pp. 130-143. Pilar Latasa,. «Transformaciones de una élite: el nuevo modelo de nobleza de letras en el Perú (1590-1621)», Manuela Cristina García Bernal, Luis Navarro García \& Julián Bautista Ruiz Rivera (coord.), Élites urbanas en Hispanoamérica (De la conquista a la independencia). Sevilla, Universidad de Sevilla, 2005, pp. 413-433.

9. Empleamos el término "Academia» en el sentido que lo hace Nieves Baranda, Cortejo a lo prohibido. Lectoras y escritoras en la España moderna, Madrid, Arco libros, 2005, p. 153; es decir, el concepto de academia no se limita a un grupo con estatutos y reuniones periódicas, sino en sentido amplio a grupos de poder social, que se reúnen esporádica o habitualmente y que tienen peso propio en los gustos y valores literarios del entorno sobre el que ejercen influencia.

10. Raquel Chang-Rodríguez, "Clarinda, Amarilis y la "fruta nueva" del parnaso peruano", en Carmen Meza \& Teodoro Hampe, La mujer en la historia del Perú, Lima, Fondo editorial del Congreso del Perú, 2007, pp. 217-234.

11. Mabel Moraña, Mujer y cultura en la colonia hispanoamericana, Pittsburgh, Instituto Internacional de Literatura iberoamericana, 1996.

12. Rolena Adorno, «El sujeto colonial y la construcción cultural de la alteridad», Revista de critica literaria latinoamericana, 1988, pp. 55-68.

13. Adorno, obra citada, p. 56

14. Ángel Rama, La ciudad letrada, Montevideo, Arca, 1998, p. 46. 
de Cervantes Saavedra ${ }^{15}$, el Laurel de Apolo (1630) de Lope de Vega ${ }^{16}$, y El Discurso en loor de la poesía (1608) de Clarinda, paratexto anónimo que aparece inserto en la Primera parte del Parnaso Antártico de obras amatorias de Diego Mexía de Fernangil ${ }^{17}$.

Si de esta lista excluimos los nombres repetidos ${ }^{18}$ y se incorporan las tres damas «que han dado en la poesía heroicas muestras» ${ }^{19}$, la nómina alcanza 42 nombres. No podemos asegurar que los 42 poetas pertenecieran efectivamente a la Academia Antártica, pues en muchos casos ni siquiera se conserva alguna obra. Las obras conservadas permiten asegurar que no se debe considerar el período colonial como la «infancia» de la Literatura hispanoamericana, sino «una literatura que participa directa y plenamente de ese "mediodía" que es

15. José Toribio Medina, Escritores americanos celebrados por Cervantes en el Canto de Caliope, Santiago de Chile, Editorial Nascimiento, 1926, Versión digitalizada en la Biblioteca Virtual Cervantes, www.cervantesvirtual.com. Conviene señalar que Cervantes considera territorio «Antártico» desde México hasta el Perú. Desde aquí consignaremos como posibles miembros de la Academia Antártica solo a aquellos que habitaron en América del Sur. Por tanto, excluimos la mención de Pedro de Alvarado, Juan de Mestanza y Ribera y Baltazar de Orena, pues vivieron en Guatemala y a Francisco de Terrazas quien vivió en México. Los poetas que menciona Cervantes en el Canto de Calíope son Diego de Aguilar y Córdova, Juan de Ávalos y Ribera, Alonso de Estrada, Rodrigo Fernández de Pineda, Gonzalo Fernández de Sotomayor, Enrique Garcés, Diego Martínez de Ribera, Pedro de Montesdoca, Alonso Picado, Sancho de Ribera y Bravo de Lagunas y Juan de Salcedo Villandrando.

16. José Toribio Medina, Escritores hispanoamericanos celebrados por Lope de Vega en El Laurel de Apolo, Santiago de Chile, Imprenta universitaria, 1922, Versión digitalizada en la Biblioteca Virtual Cervantes, www.cervantesvirtual.com. Al igual que en el caso de Cervantes (ver nota anterior), solo consignaremos a los poetas que habitaron en América del Sur. Por tanto, excluimos a Gabriel de Ayrolo Calar, Bernardo de Balbuena, Alonso de Bonilla, Martín Carrillo de Alderete, Alonso Franco y Ortega, Juan Ruíz de Alarcón y Gabriel Téllez. Lope de Vega menciona en el Laurel de Apolo a Amarilis, Juan de Arámbulo, Fernando de Avendaño, Alonso de Bonilla, Francisco de Borja y Aragón, Rodrigo de Carvajal y Robles, Alonso de Ercilla y Zúńiga, Gabriel Gómez de Sanabria, Luis Ladrón de Guevara, Fray Lucas de Mendoza, Cristóbal de la O, Pedro de Oña, Luis Pardo, Matías de Porras, Juan y Diego Rodríguez de León Pinelo, Juan de Solórzano y Pereira y Jerónima de Velasco.

17. Diego Mexía de Fernangil, Primera parte del Parnaso antártico de obras amatorias, [1608], Edición facsimilar, Roma, Bulzoni, 1990. La anónima Clarinda, en su Discurso en loor de la poesía, menciona a Diego Mexía de Fernangil, Pedro de Oña, Miguel Cabello de Balboa, Juan Salcedo Villandrando, Diego de Hojeda, Juan de Gálvez, Juan de la Portilla, Gaspar de Villarroel, Diego de Ávalos y Figueroa, Luis Pérez Ángel, Antonio Falcón, Diego de Aguilar y Córdoba, Cristóbal de Arriaga, Pedro de Carvajal, Duarte Fernández, Cristóbal Pérez Rincón, Francisco de Figueroa y Pedro de Montesdoca.

18. Pedro de Oña, Juan de Salcedo Villandrando, Diego Aguilar y Córdoba y Pedro Montesdoca.

19. Clarinda, [1608], Discurso en loor de la poesía, Edición de Antonio Cornejo Polar, y reedición de Latinoamericana editores, Lima, Universidad Nacional Mayor de San Marcos, 2000, pp. 458-459. 
la Literatura del Barroco espańol $»^{20}$. Es más, de acuerdo con Beverley, debiera reconceptualizarse como «Literatura de la época imperial» la llamada Literatura hispanoamericana de los siglos XVI y XVII ${ }^{21}$.

\section{AMARILIS PRIMICIA IMPERIAL Y SIRENA EQUINOCCIAL}

\section{Reivindicación geográfica}

La Epistola de Amarilis a Belardo, escrita alrededor de 1615, en Lima, y publicada en 1621 en Madrid por Lope de Vega dentro de La Filomena y otras diversas rimas, es una composición en metro y clave petrarquista dirigida a Belardo, seudónimo bajo el cual oculta la autora el nombre del objeto de su afecto: Lope de Vega, el poeta más popular de España. La finalidad del poema es expresar el amor que ha infundido la obra de Lope, especialmente la dramática, en la indiana Amarilis. Debe recordarse que Amarilis se enamora de Lope «de oídas»; es decir, por escuchar en el teatro las obras de Lope ${ }^{22}$. La Epístola es una obra que pertenece a un miembro de la élite ilustrada que se inserta claramente en el horizonte imperial español.

Amarilis se siente parte del imperio español: sus ancestros fueron conquistadores y defensores de la corona y así lo expresa en las estancias dedicadas a su autobiografía $a^{23}$.

En la estancia IX, se inicia propiamente la autobiografía de Amarilis. Primero señala el lugar geográfico donde vive: un imperio oculto bañado por los mares del Sur ${ }^{24}$. El Virreinato del Perú, desde donde escribía Amarilis formaba parte del Imperio Espańol y, antes, del Imperio de los Incas. La indiana emplea el adjetivo «oculto» cuyo significado está asociado tanto a «escondido» como a «desconocido». El lugar donde habita la poetisa es como ella, alguien que no se deja ver, que está escondida y que es desconocida para los ojos europeos. Amarilis se anticipa a lo que Lavallé llama "reivindicación geográfica criolla», pues con orgullo exalta un territorio ganado por sus antepasados para el imperio español ${ }^{25}$. El Sur se emplea como sinécdoque del Mar del Sur, u

20. John Beverley, Del Lazarillo al sandinismo. Estudios sobre la función ideológica de la Literatura española e hispanoamericana, Minneapolis, The Prima Institute, 1987, p. 12.

21. Beverley, obra citada, pp. 13-14.

22. Los primeros versos de la Epístola hacen referencia a ello. Véase sobre este tema Vinatea, obra citada, pp. 89-94.

23. Debe recordarse que, hasta bien entrada la administración borbónica, los españoles americanos o criollos no se sintieron parte de una estructura colonial, porque el Perú tenía la categoría jurídica de «reino».

24. Se debe recordar que, en 1532, se «descubre» el Perú. Hasta ese momento, el Imperio Incaico permaneció «oculto» a los europeos.

25. Bernard Lavallé, Las promesas ambiguas. Criollismo colonial en los Andes, Lima, Pontificia Universidad Católica del Perú - Instituto Riva Agüero, 1993, p. 111. 
Océano Pacífico ${ }^{26}$ (Estancia III, v. 37). Luego, realiza una alusión a dos personajes mitológicos: Baco y Alcides. El imperio oculto, según Amarilis, ha sido más pisado por Baco, dios del vino y la vegetación que por Alcides o Hércules, uno de los más importantes héroes griegos conocido especialmente por la realización de los doce trabajos. Probablemente, sea una referencia a lo más importante o llamativo de América: su geografía, su vegetación, su riqueza que son mayores aún que las hazañas de los conquistadores, representados por Hércules ${ }^{27}$.

145

150

155

160
En este imperio oculto que el Sur baña, más de Baco pisado que de Alcides, entre un Trópico frío y otro ardiente, adonde fuerzas ínclitas de España con varios casos y continuas lides, fama inmortal ganaron a su gente, donde Neptuno engasta su tridente en nácar y oro fino, cuando Pizarro con su flota vino, fundó ciudades y dejó memorias, que eternas quedarán en las historias. Aquí, en un valle ameno de tantos bienes y delicias lleno, que siempre es Primavera merced del dueño de la cuarta esfera, la Ciudad de León fue edificada $y$, con hado dichoso, quedó de héroes fortísimos poblada.

Sigue la localización de Lima de acuerdo con los conocimientos geográficos de la época: entre un trópico frío (Boreal o de Cáncer) y otro ardiente (Austral o de Capricornio). Precisamente, Lima y Madrid se encuentran sobre los Trópicos. Amarilis llama a los conquistadores «fuerzas ínclitas de España» y asegura que han ganado fama inmortal (como Hércules) por sus hazañas. Ellos llegaron al lugar donde Neptuno engasta su tridente con nácar y oro fino, el proverbial oro del Perú. Cuando Pizarro llegó, fundó ciudades, y su fama se extendió y quedará para siempre en la historia. Luego mediante el deíctico "aquî" ofrece una referencia a la fundación de Huánuco, la Ciudad de los caballeros de León. También alude al clima benigno del lugar que pareciera en eterna primavera, gracias a Apolo, el dueńo de la cuarta esfera; es decir, el sol. La mencionada ciudad quedó poblada de héroes fortísimos, una referencia a «los de Huánuco», fuerzas siempre leales al rey de España. Debe notarse la manera como aparecen los elementos que identificarán a Amarilis, que van de lo general -el imperio oculto, el mar del Sur, la conquista de Pizarro- a lo particular: el lugar de su nacimiento, la Ciudad de los Caballeros de León.

26. Citaremos siempre por mi edición dela Epístola de Amarilis a Belardo, ya citada.

27. No debe olvidarse que la corona española estaba representada por las columnas de Hércules, elemento iconográfico característico del Non Plus Ultra de la Casa de Austria. 
En la X estancia, continúa la información sobre Huánuco contenida en la estrofa anterior. Se inicia con dos referencias históricas vinculadas con la ciudad de Huánuco, supuesto lugar de nacimiento de la autora: frontera de bárbaros y terror de tiranos que intentaron conspirar contra el rey. A Huánuco se la consideraba «frontera de bárbaros», pues cerca del río Huallaga (que atraviesa los actuales departamentos de Huánuco, San Martín y Loreto), en la región llamada Rupa-Rupa, habitaban los indios panatahuas que impidieron la avanzada española sobre la zona. El adjetivo «bárbaros» empleado por Amarilis se vincula especialmente con la idea de «salvaje». La segunda referencia es a los encomenderos de Huánuco, capitaneados por Juan de Saavedra, quienes ayudaron a vencer a las huestes de Gonzalo Pizarro en Jaquijahuana, en 1548, y luego, al mando de Gómez Arias de Dávila, lograron sofocar la rebelión de Francisco Hernández de Girón, en la batalla de Pucará28, Jauja, en 1553. La indiana muestra aquí el espíritu de lo que García Bedoya llama "posesión exclusivista ${ }^{29}$. Amarilis es heredera de los «beneméritos» conquistadores $\mathrm{y}$, como la mayoría de los criollos, siente arraigo por la tierra americana. Sin embargo, como también es usual en las élites criollas, es poco receptiva a la herencia cultural nativa ${ }^{30}$.

Es frontera de bárbaros y ha sido
t65 lerror de los tiranos, que intentaron
contra su Rey enarbolar bandera,
al que en Jauja por ellos fue rendido
su atrevido estandarte le arrastraron,
y volvieron el reino a cúyo era.
Bien pudiera, Belardo, si quisiera,
en gracia de los cielos,
decir hazañas de mis dos abuelos
que aqueste nuevo mundo conquistaron,
y esta ciudad también edificaron
do vasallos tuvieron,
y por su rey su vida y sangre dieron,
mas es discurso largo
que la fama ha tomado ya a su cargo,
si acaso la desgracia desta tierra
que corre en este tiempo
tantos ilustres méritos no entierra.

Luego, inicia propiamente el recuento biográfico con la referencia a sus ancestros: los dos abuelos. Amarilis le asegura a Belardo que podría narrarle las hazañas de sus dos abuelos, conquistadores del Nuevo Mundo, que edificaron Huánuco, la ciudad de los Caballeros de León, y que dieron su vida y su sangre

28. José Varallanos, Historia de Huánuco. Introducción para el estudio de la vida social de una reunión del Perú. Desde la era prehistórica hasta nuestros días, Buenos Aires, Imprenta López, 1959, pp. 143-157.

29. Carlos García Bedoya, La literatura peruana en el periodo de estabilización colonial, Lima, Fondo editorial de la Universidad Nacional Mayor de san Marcos, 2000, p. 52.

30. García Bedoya, obra citada, p. 59. 
por el rey; es decir, que participaron en el apresamiento de Gonzalo Pizarro y de Hernández de Girón. Sin embargo, empleando el tópico de la modestia, se excusa afirmando que ese es un largo discurso que la fama ya ha tomado a su cargo.

Ahora bien, la poetisa muestra cierta prevención frente al hecho de que por los años en que fue escrita la Epistola, aproximadamente $1615^{31}$, la situación política descrita como «desgracia de estas tierras» sepulte en el olvido los méritos de sus ilustres antepasados. Al respecto, José Durán asegura:

Era un lugar común estimar las proezas de los conquistadores sobre las de sus abuelos de la Reconquista. Y en ese lugar común había mucha amarga protesta, desilusión y muchas veces resentimiento. Porque ni las hazañas ni el dinero ganado les sirvieron para alcanzar honra y nobleza, como en los tiempos antiguos. Las concesiones nobiliarias obtenidas fueron mínimas, y algunas de ellas sólo valían en tierra americana. De vuelta a España, el indiano sufría por lo general burlas y rechazo. Pero, en cambio, en América supo convertirse en señor: los conquistadores y los primeros pobladores -fundadores de ciudades-, ahora vecinos y encomenderos, pasan a ser la máxima aristocracia de la tierra. Al convertirse, pues, en nobles de hecho, ricos en caudal, poder y fama, ven colmadas sus aspiraciones originales aun cuando empiecen a sentirse mal pagados por la corona. Y así, la transformación quedaba consumada ${ }^{32}$.

\section{Amarilis innovadora de modelos poéticos}

Amarilis es capaz de innovar los modelos poéticos en boga: asume y valora las tradiciones venidas de la península, y se siente tan igual a los poetas peninsulares que hasta innova la tradición epistolar y petrarquista Así lo muestra el hecho de construir una Epístola en una forma poética distinta de la preceptuada para este tipo de composición: el terceto encadenado.

Valga mencionar que existe una polémica respecto de la inclusión del poema de Amarilis dentro del grupo «Epístola». Patrizia Campana asegura que el poema no es una epístola, sino solo una canción petrarquista y el incluirla bajo el título de epístola se debe a la indefinición del género epistolar, al descuido de Lope y al hecho de que en el conjunto de las epístolas que aparecen en La Filomena se mezclen obras de distinto tipo bajo el mismo marbete de "Epístola» ${ }^{33}$. Los argumentos centrales que cita la autora se vinculan con el estilo y características del género epistolar y de la canción petrarquista. Respecto del primer tema, Campana asegura que el estilo de Amarilis en su composición es el elevado, que corresponde al uso habitual en la canción petrarquista; prueba de ello es el uso del "tú" (elevado) en lugar del "vos" (coloquial). Si

31. Guillermo Lohmann, Amarilis indiana, Identificación y semblanza, Lima, Pontificia Universidad Católica del Perú, 1993, pp. 68-73 y 227.

32. José Durán, La transformación social del conquistador, Lima, Editorial Nuevos rumbos, 1958, p. 98.

33. Patrizia Campana, "La polémica "Epístola" de Amarilis a Belardo", Anuario Lope de Vega 3, 1997, pp. 7-24. 
bien en términos generales coincidimos con Campana, la prueba que ofrece no es tal, pues como lo asegura Lapesa, en América, desde inicios del siglo XVII, las cortes virreinales adoptaron y difundieron cambios en tratamientos de respeto: el uso del "vuestra merced > usted" como tratamiento de respeto y el uso del tú como forma coloquial ${ }^{34}$. Por ello, los lugares que fueron sedes de los principales virreinatos, como México y el Perú, eliminaron el voseo. Entonces, es muy probable que el "tú" de la epístola responda a un tratamiento más bien cercano y familiar. Sobre las características del género, Campana, a pesar de ser consciente de la indefinición del género epistolar, no toma en consideración que el tipo de composición en el que se debe escribir la epístola no está preceptuado ni acepta una posible transgresión o desconocimiento de Amarilis de la normativa del género.

Respecto de la polémica iniciada por Campana de si es o no una epístola, consideramos que se debe separar la estructura estrófica de la finalidad pragmática; es decir, el poema de Amarilis es una canción petrarquista en tanto forma estrófica; sin embargo, su finalidad pragmática es epistolar en tanto cumple con las características más relevantes de la epístola: es una comunicación dirigida a un tú, el emisor está determinado, existe el deseo de que su destinatario conozca un conjunto de informaciones del emisor, se formula un pedido y, por último, se escribe un envío.

El género clásico epistolar, al estar vinculado con una forma habitual de comunicación -la carta- y al estar caracterizado por su indeterminación, logró establecerse cuando se reiteraron los rasgos comunes y se fijó una preceptiva. Los rasgos comunes de la epístola literaria están vinculados con la intención comunicativa y una estructura de contenido básica: vocativo, cuerpo y despedida.

Así, la estructura de la Epistola revela precisamente su carácter epistolar, pues contiene todas las partes que componen el modelo retórico medieval. Sin embargo, el orden no es el canónico. El iniciar con el exordium probablemente se deba a la necesidad de poner al destinatario en «autos» respecto del emisor. Debe recordarse que las epístolas son usuales entre personas conocidas, entre las que existe una relación amical. En el caso de la epístola que nos ocupa, emisora y destinatario no se conocen; por ello, la comunicación se inicia con una exposición de cómo Amarilis ha conocido a Lope y cuál es su intención: iniciar una relación entre ellos.

Por otro lado, en la tradición epistolar española, se recurrió especialmente a los tercetos encadenados o a la lira como formas estróficas usuales. Sin embargo, el metro en el que debe escribirse una epístola no está preceptuado. Consideramos que la Epistola de Amarilis a Belardo presenta como innovación la elección de la forma estrófica, una canción petrarquista ${ }^{35}$, la cual es la

34. Rafael Lapesa, Historia de la lengua española, Madrid, Gredos, 1986, p. 579.

35. Este tema ha sido desarrollado por Vinatea en 1987, Tesis para optar el grado de bachiller en Lingüística y Literatura, Pontificia Universidad Católica del Perú; Sabat de Rivers en 1990, "Amarilis y la epístola horaciana», Hispanic Review 58, pp. 455-467; y Campana en 1997, 
preferida en la tradición pastoril para cantar al amor y que también se adecua perfectamente a la elección de los nombres literarios de la autora, "Amarilis» y del destinatario, «Belardo». Se debe considerar también el hecho de que si no fuera una epístola, ¿por qué la habría contestado Lope con otra epístola?

Por otro lado, al optar por una forma estrófica diferente de la habitual no se aleja del género epistolar, sino más bien lo innova y lo enriquece. Una muestra de esta innovación es la petición propia de las epístolas y que, hasta donde hemos podido indagar, no tiene precedentes en ninguno de los poetas hispanos y novohispanos que escribieron canciones. Asimismo, otra innovación es el empleo de la estrofa final que la epístola poética utiliza como conclusio, despedida y envío y la canción petrarquista solo como envío.

A pesar de que aún no está determinada la identidad de la poetisa ${ }^{36}$, Sabat de Rivers ${ }^{37}$ (1990: 460) afirma que también podría aceptarse la idea de que este alejamiento de la pauta formal puede significar una marca que podría ser de sexo: la mujer escribe de una manera distinta de la del hombre. Además, Chang-Rodríguez ${ }^{38}$ ha llamado la atención respecto de dos temas importantes: lo poco frecuente que resulta encontrar en esta época cartas de mujeres poetas que se dirigieran a autores y, sobre todo, que Amarilis, tan embebida de la tradición petrarquista, exprese una forma contraria al modelo privilegiado de mujer pasiva y silente. No coincidimos con estas afirmaciones, más bien pensamos que se trata de un caso en el que se ha evitado la transgresión del espacio literario ocupado por el hombre, de ahí que escriba bajo un seudónimo.

artículo citado. La forma literaria que la mayoría de críticos asignaron a la Epistola fue una silva debido a que Marcelino Menéndez Pelayo en su Historia de la literatura hispanoamericana, 1913, fue el primero en mencionar erróneamente esa forma métrica: «Una elegante epístola en silva». No hace más observaciones métricas sobre el particular. La opinión de Menéndez Pelayo fue seguida sin más por la mayoría de críticos que mencionan la Epistola. Sin embargo, ya en 1962, Aurelio Miró Quesada Sosa en su obra Lope de Vega y el Perú se refiere a la Epístola como: «silva o mejor dicho una canción a la manera petrarquista». Autores posteriores, Vinatea, Sabat, Campana han reconocido que se trata de una canción petrarquista; sin embargo, Lohmann, en su estudio histórico en el que intenta identificar a Amarilis, sigue refiriéndose a la Epistola como «silva». La Epistola de Amarilis a Belardo, en tanto estructura estrófica, es una canción que combina a lo largo de sus diecinueve estrofas versos endecasílabos y heptasílabos, combinación propia de la llamada canción italiana o petrarquista. En cada estrofa, se combinan catorce versos endecasílabos y cuatro heptasílabos, el último de ellos «blanco» o sin rima, habituales también en este tipo de composición. Asimismo, un elemento esencial en la canción es la estancia que requiere de una rigurosa simetría y la recurrencia a una misma pauta formal, es decir, una vez estructurada la primera estancia, las siguientes deben seguir la misma estructura. En la canción, además de las estancias, generalmente existe una estrofa que repite una parte o es un equivalente de las estancias. A esta estrofa se la llama Commiato o envío, y se caracteriza por contener una fingida interpelación a la canción misma.

36. Véase sobre este tema mi hipótesis de autoría en la edición de la Epistola, pp. 29-31.

37. Georgina Sabat de Rivers, «Amarilis y la epístola horaciana», Hispanic Review 58, 1990, pp. $455-467$.

38. Raquel Chang-Rodríguez, "Clarinda, Amarilis y la "fruta nueva" del parnaso peruano», Carmen Meza \& Teodoro Hampe, La mujer en la historia del Perú, Lima, Fondo editorial del Congreso del Perú, 2007, pp. 217-234. 
Además, por ser la epístola un tipo de comunicación personal y privada, la transgresión es nula; es decir, no se ha alejado mucho del modelo privilegiado de mujer pasiva y silente.

Finalmente, podemos afirmar que la Epistola de Amarilis a Belardo por la elección de la forma estrófica y por el contenido mismo representa una fusión de la epístola y la canción petrarquista.

\section{Amarilis y la resemantización americana de la tradición hispánica}

Desde la primera estancia de la Epistola, se pueden rastrear debates medievales y renacentistas. El primero de ellos es el conocido debate entre cuál es el mejor de los sentidos, la vista o el oído, que se resuelve a favor del oído, pues Amarilis se ha «aficionado» a Lope mediante el conocimiento de su obra dramática: ha leído (probablemente en voz alta) o ha escuchado, por lectura o recitación de parlamentos, la obra del Fénix de los ingenios y de ese conocimiento ha surgido el amor:

\footnotetext{
Tanto como la vista, la noticia de grandes cosas suele las más veces al alma tiernamente aficionarla.
}

El amor que Amarilis manifiesta sentir por Belardo se adecua a la idea de amor cortés ${ }^{39}$, concebido como un amor separado de la posesión física cuyo objetivo es, más bien, la manifestación misma del amor y evidenciar que profesa la teología del amor y, por tanto, tiene en el amado a "su único dios». Ahora bien, lo interesante en la Epistola es que los ideales cortesanos están reconvertidos, pues el objeto de amor no es una mujer, sino un hombre.

En la segunda estancia, se presentan dos de los temas clásicos del amor cortés: el amor inalcanzable, imposible y lejano, «amour lointain», y el sufrimiento que ese amor acarrea, «bendito sufrimiento». Un amor que se sustenta sin esperanza alguna es, en palabras de Amarilis, «una fineza rara» (Estancia II, vv. 20 y 21) y siente que su alma osada fue criada para esa alteza (Estancia II, v. 29); sin embargo, ese amor dificultoso la desvela y la lastima.

La religión del amor, «service d'amour», también tiene presencia en la Epistola. Amarilis le ofrece sus "primicias» (Estancia V, v. 84); es decir, la oblación, los primeros frutos que tradicionalmente se entregaban a Dios. Dentro de esta religión del amor, otro tema interesante planteado en las tres estancias siguientes es el de «la amada como obra de Dios» ${ }^{40}$ que Amarilis ha reconvertido en «el amado como obra de Dios», tema místico por excelencia de larga tradición literaria. Amarilis se refiere, en primer lugar, al estilo milagroso

39. Sobre los temas vinculados al amor cortés, véase Otis Green, España y la tradición occidental, Madrid, Gredos, 1969.

40. María Rosa Lida de Malkiel, Estudios sobre la literatura española del siglo XV, Madrid, José Porrúa Turanzas, 1977, pp. 179-290. 
de Belardo (Estancia III, v. 39), luego a Belardo mismo como milagro (Estancia IV, v. 56) y, finalmente, como el poeta más importante por su origen divino (Estancia VI, v. 95), y dan prueba de ello la consagración que las mil deidades le proporcionan (Estancia V, v. 74).

El amor que la indiana siente por Belardo ha surgido por el aprecio que ella siente a la belleza de su obra. Ese amor se convierte en religión. Además, ese amor contiene otro ingrediente básico dentro de este estilo: es un amor lejano, inalcanzable, imposible; por ello, el amor se ennoblece y constituye el patrimonio de los «bien nacidos» y de "las almas osadas que para mayor alteza fueron criadas» (Estancia II, v. 28 y 29). Ahora bien, esto no significa que Amarilis exprese su amor únicamente como una abstracción. Ella ama y desea a Belardo, tanto así que su voluntad le ofrece «un alma pura a su valor rendida» y, más aún, los favores del cielo y toda su corporeidad disfrazada de elementos suntuarios propios del léxico petrarquista: sus cabellos (oro), sus brazos y cuello (marfil), sus dientes (perlas), sus labios (balajes), sus mejillas (corales), su rubor (amatistas), su inmaculada pureza (su tesoro) y dichosos sucesos en Acidalia, la fuente donde se bañaba Venus (Estancia XV).

\begin{tabular}{ll} 
& \multicolumn{1}{c}{ Finalmente, Belardo, yo te ofrezco } \\
& una alma pura a tu valor rendida, \\
& acepta el don, que puedes estimallo, \\
& y dándome por fe lo que merezco \\
& quedará mi intención favorecida \\
de la cual hablo poco y mucho callo, & y para darte más, no sé ni hallo. \\
& Dete el cielo favores; \\
& las dos Arabias, bálsamo y olores; \\
& Cambaya sus diamantes; Tibar oro; \\
& marfil Cefala; Persia su tesoro; \\
& perlas los Orientales; \\
el rojo mar finísimos corales; & balajes los Ceilanes; \\
& aloe precioso Sarnaos y Campanes; \\
rubíes Pegugamba; y Nubia algalia; & \\
amatistas Narsinga; \\
y prósperos sucesos Acidalia.
\end{tabular}

Asimismo, a partir del léxico de la Epístola, y del conocimiento de los libros que circularon en los primeros tiempos de la Colonia, se puede realizar una pesquisa de los autores que influyeron en Amarilis.

En primer lugar, conviene mencionar la influencia de Enrique Garcés, el poeta, minero y arbitrista portugués avecindado en el Perú desde los primeros años de la Colonia. El influjo de Garcés se puede notar en la forma estrófica y el conocimiento de los paradigmas de las canciones petrarquistas, pues él tradujo el Cancionero de Petrarca de la lengua toscana a la española (Petrarca 1591). Además, Garcés también tradujo Los Lusíadas de Camoens del portugués al español (Camoens 1591). El influjo de esta traducción se puede observar 
con toda claridad, pues los topónimos y términos geográficos mencionados en la Epistola, con excepción de los vinculados estrictamente al Perú, están mencionados en Los Lusiadas ${ }^{41}$.

Asimismo, de acuerdo con las investigaciones históricas del comercio de libros durante los siglos XVI y XVII y el estudio de las bibliotecas particulares de la época, citados anteriormente, se puede determinar cuáles eran los autores favoritos de la época42. Entre ellos, Fray Luis de Granada, con su Introducción del simbolo de la fe, ocupa un lugar privilegiado. Se puede rastrear la influencia de este autor en la estancia I en el debate entre la vista y el oído y en el uso de acepciones de términos poco usuales en la época, de acuerdo con las concordancias que ofrece el Corpus Diacrónico del Español de la Real Academia Española, en adelante (CORDE), como «aficionar», «virtud», «artificioso», "pueril», "tesoro» que están usados con las mismas acepciones y en contextos similares a los de la indiana; construcciones como «sombra de muerte» y la referencia a Santa Dorotea. Respecto de esta última referencia, conviene citar también Santiago de la Vorágine, con su Leyenda dorada y Flos Sanctorum de Alonso de Villegas, 1593. En esta última obra, en el Discurso 49, "De martirio», señala como ejemplo el martirio de Santa Dorotea. También Diego de Hojeda, en La Cristíada, se refiere al martirio de la santa ${ }^{43}$.

También se puede ver la influencia de Los diálogos de amor de León Hebreo (probablemente en la traducción que el Inca Garcilaso hiciera en el año 1586) especialmente en el debate del mejor de los sentidos, vista u oído. Ya se ha mencionado que Amarilis, por la manera como ha conocido a su amado, se inclina por el sentido del oído:

Y la [hermosura] que se alcanza por el oído es la imagen de la hermosura del ánima del mundo, porque consiste en concordancia, armonía y orden, así como existen las formas en ella en ordenada unión. [...] pero gracia que deleite y mueva el ánima a propio amor que se llama hermosura no se halla en los objetos de los tres sentidos materiales, que son gusto, olfato y tacto, sino solamente en los objetos de los dos sentidos espirituales, vista y oído. [...] Y también se halla en los objetos del oído, como hermosa oración, linda voz, linda habla, hermoso canto, linda música, bella consonancia, linda proporción y armonía; en la espiritualidad de las cuales cosas se

41. Acidalia (VIII, 64; IX, 52); Arabia (III, 72; IV, 63, 101; VI, 25; X, 100, 103, 135); Cambaya (VII, 21; X, 29, 34, 72,106); Ceilán (VII, 19; IX, 14; X, 107, 136); Champá, Campá o Campanes (X,129); Narsinga (VII, 21; X, 14, 108,120); Pegú o Pegugamba (X, 122); Persia (IV, 102; X, 100, 103); Pindo (III, 2); Sofala o Cefala (I, 54; V, 73; X, 94); Tebas (IX, 19); Zelandia (VII, 61). Términos geográficos: Antártico (I, 51; V, 50, 65; VIII, 67; X, 141); Clima (I, 29; II, 109; V, 38, 70; VIII, 68; X, 151); Esfera (II, 33, 34; IV, 69; IX, 86); Oriental (I, 8, 52; IV, 23; V, 69; VII, 52; X, 13); Polo (I, 24; II, 34, 105; III, 8,45; V, 13, 14, 15, 19, 50, 65; VI, 27 , 76; X, 139, 141); Sur V, 77; VI, 97; X, 39, 107, 134); Trópico (VIII, 72; X, 129); Zona (III, 6). Obsérvese que la mayoría de los topónimos están concentrados en un canto, el décimo, al igual que en el caso de la Epistola de Amarilis a Belardo, donde están concentrados en la estancia XV.

42. Véase la Biblioteca de Amarilis en http://www.estudiosindianos.org/

43. Diego de Hojeda, [1511], La Cristíada, Madrid, EDIBESA,1996. 
halla la gracia, que mueve al ánima a delectación y amor, mediante el sentido espiritual del oír ${ }^{44}$. (Hebreo 1996 [1590]: 298)

Por otro lado, se puede comprobar también la influencia de los Diálogos en la idea del amor y el deseo, pues Amarilis ama a Belardo y también lo desea:

[...] el amor es deseo de unión con la cosa amada, y declaramos de qué manera todo deseo es amor y todo amor es deseo. Y según aquello te he definido el amor en común que es deseo de alguna cosa. (Hebreo 1996 [1590]: 298)

Ahora bien, el autor más popular de la época fue Lope de Vega cuyas comedias circularon tanto en cuadernillos sueltos como en las famosas partes. También gozaron de gran popularidad La Arcadia, 1598; Los pastores de Belén, 1612; El Isidro, 1599; La hermosura de Angélica, 1602; El peregrino en su patria, 1604; y las Rimas sacras, 1614. En la Epistola, se mencionan directamente $L a$ hermosura de Angélica y El peregrino en su patria. El nombre «Belardo» también se extrajo de las obras de Lope, quien lo usaba a manera de alter ego pastoril en El peregrino en su patria, Los pastores de Belén, La Arcadia, El nacimiento de Ursón y Valentín, y en la cuarta y quinta parte de Flor de Romances. Referencias poco usuales como la del gramático alejandrino Aristarco quien se «atrevió» a corregir los versos de Homero que están presentes en La Dragontea, 1598. Conviene seńalar que, además de la referencia propiamente al gramático, existe coincidencia en la imagen de las flechas malignas que este dispara. También llama la atención el uso de "Himeneo» como sinécdoque de matrimonio, referencia poco usual en la época, que Lope empleó en El peregrino en su patria y en sus Rimas sacras. Entre los topónimos, Lope emplea el topónimo Cambaya y también las dos Arabias (no las tres como era la referencia usual), del modo que lo hace Amarilis.

Otras influencias importantes que se advierten en la Epistola son las del conjunto de escritores incluidos en Flores de baria poesía, especialmente, en el caso de Juan de la Cueva y Gutierre de Cetina.

Finalmente, Amarilis debió leer a los poetas indianos: Mexía de Fernangil, Dávalos Figueroa, Pedro de Ońa, Diego de Hojeda, Diego de Aguilar y de Córdoba y al Inca Garcilaso de la Vega pues se pueden encontrar en la Epistola referencias al Perú, términos y giros lingüísticos empleados por estos poetas.

En suma, en su Epistola, Amarilis, destacada mujer escritora e integrante de la llamada Academia Antártica, escribe en clave petrarquista una epístola amorosa a Lope de Vega. Las expresiones discursivas que se reconocen a lo largo del poema revelan la ambigüedad de lo que se ha llamado el «sujeto criollo». Por un lado, se evidencia la identificación de Amarilis con el imperio

44. León Hebreo, [1590], Los diálogos de amor, Traducción del Inca Garcilaso de la Vega, Madrid, Biblioteca Castro, 1996. 
espańol de la que se siente "primicia»: la indiana es nieta de conquistadores y de los defensores del Imperio español y depositaria legítima de los códigos culturales: se nutre y sigue las tradiciones venidas de la península y hasta innova la tradición epistolar y petrarquista. Es una acuciosa conocedora de los modelos humanistas y se adhiere a la norma lingüística peninsular. Es decir, asume y valora las tradiciones venidas de la península, y se siente tan igual a los poetas peninsulares tanto es así que innova la tradición epistolar y petrarquista. Sin embargo, Amarilis ha nacido en el Nuevo Mundo y, por ello, se siente diferente, «sirena equinoccial», que se enorgullece de su tierra y del legado de sus antepasados, y también sufre por la falta de reconocimiento de las proezas que los conquistadores realizaron. Primicia del Imperio español y sirena equinoccial que con su canto despierta el interés del Fénix de los ingenios y, definitivamente, una precursora de la aún no escrita historia de la Literatura femenina en el Perú. 